\title{
Peak Strain Calculation Equation of Recycled Aggregate Concrete
}

\author{
Li ZHOU \\ College of Civil Engineering and Architecture \\ Guangxi University \\ Nanning, China \\ e-mail: 1zhou5@gzu.edu.cn
}

\author{
Yisheng SU \\ College of Civil Engineering and Architecture \\ Guangxi University \\ Nanning, China \\ e-mail: suyisheng@gxu.edu.cn
}

\begin{abstract}
Peak strain of concrete is an important mechanical parameter. Previous studies have found that the peak strain of recycled aggregate concrete (RAC) is significantly different with natural aggregate concrete (NAC). This paper collected peak strain test data of domestic and foreign scholars and derived the calculation equation of RAC peak strain by using the method of modifying the NAC peak strain equation. The new calculation equation involved the parameter of recycled aggregate (RA) replacement ratio and could be suited for both RAC and NAC. The calculation results show that the new equation's calculated value has a high degree of similarity with the test data. The results of this study can provide a reference value for the recycled aggregate concrete application in structure engineering.
\end{abstract}

Keywords-recycled aggregate concrete; peak strain; affecting factors; calculation equation

\section{INTRODUCTION}

Recycled aggregate concrete (RAC) is reuse of construction and demolition waste as recycled aggregates (RA) in new concrete. It is beneficial from the view point of environmental protection and resources reservation. Over the past 100 years, the study of recycled aggregate concrete has achieved fruitful research results and some practical engineering also applied it.

Previous studies have shown that RAC has the characteristics of low strength, high strain and high brittleness compared with natural aggregate concrete (NAC). P.J.Nixon [1] listed out the results of RAC studied by scholars before 1978, and pointed out the compressive strength of concrete with RA is generally decreased compared with NAC. T.C.Hansen [2] summarized the existing test results of RAC and generally accepted that when natural sand is used, up to $30 \%$ of natural crushed aggregate can be replaced with coarse recycled aggregate without significant changes in the mechanical properties of concrete. The peak strain of RAC not only reflects the basic characteristics but also an important data for stress-strain curve, at present, the research on peak strain is still limited. G-F.Belén et al [3] studied on the volumetric strain of RAC and found that when the test is performed in load control rate, the maximum volumetric strain values increase with increasing percentages of recycled aggregate, whereas when the test is performed in strain control rate these maximum values decrease. In any case, the concretes with $20 \%$ replacement of the coarse aggregate have stress-volumetric strain curves and critical stress values very similar to those of conventional concretes. W. George et al [4] took RAC with different coarse aggregate replacement rate as the test specimen and pointed out that the peak strain corresponding to the maximum stress increases when increasing the RA replacement ratio. A new formula for calculating the peak strain of RAC is also proposed. M-L.Isabel et al [5] had obtained the stress-strain curves of each specimen with different RA replacement rate, the test results shown that failure strain was likewise observed to rise with the replacement rate, from $2.1 \%$ in the concrete with no recycled aggregate to $2.3 \%$ in the material with $50 \%$ recycled gravel and $2.5 \%$ when only recycled aggregate was used. T.Du et al [6] designed 12 prism specimens of 150 $\mathrm{mm} \times 150 \mathrm{~mm} \times 450 \mathrm{~mm}$ with the target compressive strength of C35, C45, C55 and C60. The complete stress-strain curves of RAC specimens were obtained by the experiment, and the shape of the complete stress-strain of RCA is similar with that of NAC, but the peak strain of RAC is much higher than that of NAC. Other scholars [7-14] have also carried out research on the peak strain of recycled aggregate concrete.

\section{COLLECTION AND ANALYSIS OF RAC PEAK STRAIN TEST DATA}

\section{A. Collection of Peak Strain Test Data}

In this paper, 6 groups experimental data of RAC which studied by scholars were collected, all data was published in authoritative journals [15-20]. In order to achieve the research goal of peak strain, the following principles should be abided in the aspect of test data collection.

1. The experimental data sources: domestic and international authoritative academic journals.

2. Each set of test data at least consists of two or more than two data.

3. The test data in each group had at least one sample which recycled aggregate replacement rate is $0 \%$.

4. Test specimens did not add ceramic, asphalt and other aggregate.

5. Recycled aggregate of test specimens have not been improved.

The details of all collected test data which used for proposing the equation of RAC peak strain are presented in Table I 
TABLE I. DETAILS OF COLLECTED Test DATA

\begin{tabular}{|c|c|c|c|}
\hline Literature & $\begin{array}{c}R A \\
\text { replacement } \\
\text { rate }\end{array}$ & $\begin{array}{c}\text { Prism } \\
\text { compressive } \\
\text { strength }(\mathrm{MPa}) \\
\end{array}$ & $\begin{array}{l}\text { Peak strain } \\
\left(x 10^{-3}\right)\end{array}$ \\
\hline \multirow{5}{*}{$\begin{array}{l}\text { Z.H. Deng } \\
{[15]}\end{array}$} & 0 & 32.63 & 1.639 \\
\hline & 0.3 & 30.25 & 1.683 \\
\hline & 0.5 & 28.47 & 1.940 \\
\hline & 0.7 & 29.09 & 2.126 \\
\hline & 1 & 21.56 & 2.196 \\
\hline \multirow{5}{*}{ J.Z. Xiao [16] } & 0 & 26.90 & 1.873 \\
\hline & 0.3 & 25.40 & 1.910 \\
\hline & 0.5 & 23.60 & 1.949 \\
\hline & 0.7 & 24.20 & 2.058 \\
\hline & 1 & 23.80 & 2.225 \\
\hline \multirow{4}{*}{$\begin{array}{c}\text { J.H. Zhou } \\
\text { [17] }\end{array}$} & 0 & 36.70 & 2.096 \\
\hline & 0.3 & 31.40 & 1.846 \\
\hline & 0.5 & 27.00 & 1.379 \\
\hline & 0.8 & 24.50 & 2.180 \\
\hline \multirow{2}{*}{ L. Jin [18] } & 0 & 31.80 & 1.790 \\
\hline & 1 & 25.60 & 2.080 \\
\hline \multirow{4}{*}{$\begin{array}{c}\text { Paula Folino } \\
{[19]}\end{array}$} & 0 & 36.52 & 1.840 \\
\hline & 0.3 & 33.59 & 1.640 \\
\hline & 0.6 & 30.42 & 1.730 \\
\hline & 1 & 29.10 & 2.050 \\
\hline \multirow{3}{*}{$\begin{array}{l}\text { H.F. Yang } \\
\text { [20] }\end{array}$} & 0 & 18.10 & 1.917 \\
\hline & 0.5 & 20.84 & 2.056 \\
\hline & 1 & 16.87 & 2.353 \\
\hline
\end{tabular}

\section{B. Analysis of Peak Strain Test Data}

Based on the collected test data, the relationships among the peak strain, prism compressive strength and RA replacement level were discussed in this paper. Figure 1 shows the relationship between peak strain and prism compressive strength.

It can be seen from Fig. 1 that for the same prism compressive strength, there is a quite different on the peak strain; this reflects the differences of each test specimen in the production. When the compressive strength is in the range of $15 \mathrm{MPa}$ to $40 \mathrm{MPa}$, the peak strain ranges between $1.5 \times 10^{-3}$ and $2.5 \times 10^{-3}$. From the whole distribution of test data, the RAC peak strain decreased with the increasing of prism compressive strength, this is the reverse of NAC. So in the process of structural analysis and design, the peak strain of RAC cannot be replaced by the peak strain of NAC.

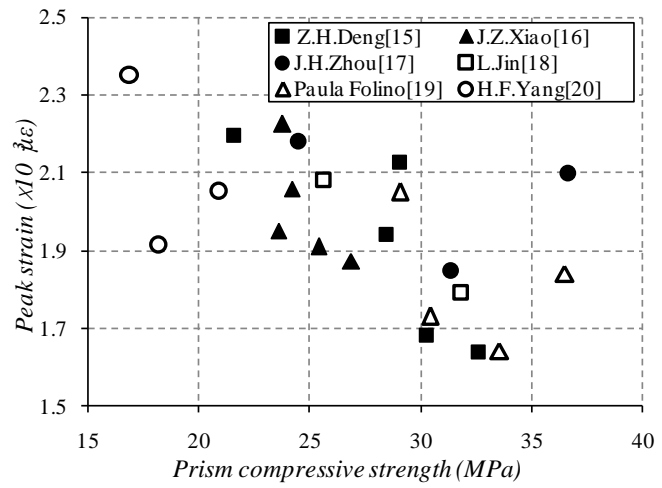

Figure 1. The relationship between peak strain and prism compressive strength of RAC

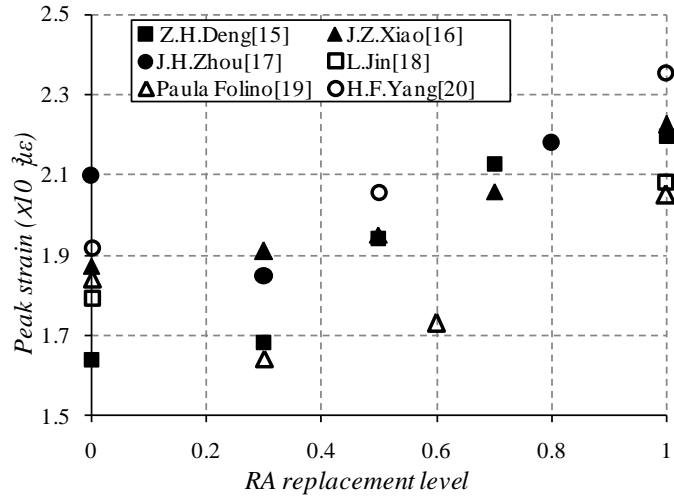

Figure 2. Effect of RA replacement level on the RAC peak strain, based on collected test data

Fig. 2 presents the effect of RA replacement level on the peak strain. 4 groups of experimental data reflect the same rule that the RAC peak strain increased with the improvement of RA replacement level, the other 2 groups of experimental data have an inflection point when the RA replacement level is $30 \%$. This figure also shows that the maximum peak strain for RAC with $100 \%$ RA content was around 35\% higher than that of the corresponding NAC. All of these indicate that the replacement rate of RA has a significant effect on the peak strain.

The relationship between prism compressive strength and RA replacement level is shown in Fig. 3. Similarly to the RAC peak strain which shown in Fig. 2, the prism compressive strength is also related to the replacement rate of RA, among the collected test data, there are 5 groups showed that the RAC prism compressive strength decreased with the increasing of RA replacement rate, only 1 group data showed that the compressive strength increased when the replacement rate is $50 \%$. The compressive strength for RAC with $100 \%$ RA content was around 7\% 34\% lower than that of the corresponding NAC, All groups of the test data showed the variation characteristics of nonlinear even though the variation range of some groups is not significantly.

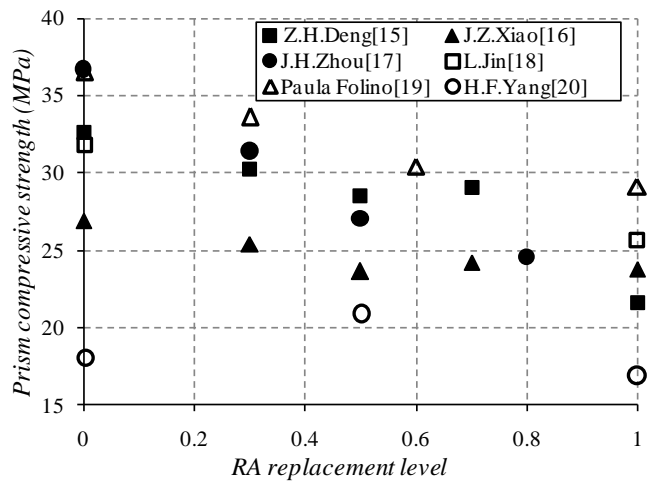

Figure 3. Effect of RA replacement level on the prism compressive strength, based on collected test data 


\section{CALCULATION EQUATION}

\section{A. Research Method}

Up to now, the study on calculation equation of the peak strain for RAC is still rare. J.Z.Xiao [16] suggested the calculation equation of peak strain by fitting the experimental data; the equation is given by the following expression:

$$
\begin{gathered}
\varepsilon_{c, r}=\left\{0.00076+\left[\left(0.626 f_{c, r}-4.33\right) \times 10^{-7}\right]^{0.5}\right\} \times\left(1+\frac{r}{B}\right) \\
B=65.715 r^{2}-109.43 r+48.989
\end{gathered}
$$

Where ${ }^{\varepsilon_{c, r}}$ is the peak strain of RAC, $f_{c, r}$ is the prism compressive strength, $r$ is the RA replacement rate.

The disadvantages of equation (1) is lacking in the support of more experimental data, in order to get a better calculation equation of peak strain, this paper establishes a new equation according to the following steps:

1. Collect a large number of test data according to the principle of data collection in this paper.

2. Establishing the ratio relationship between RAC with different RA content and NAC on compressive strength. (Relationship 1 in Fig. 4)

3. Establishing the ratio relationship between RAC with different RA content and NAC on peak strain. (Relationship 3 in Figure 4)

4. Selecting the general calculation equation of peak strain according to literature [21] and Chinese code [22]. (Relationship 2 in Fig. 4)

5. Establishing the calculation equation of RAC peak strain according to the relationships shown in Fig. 4.

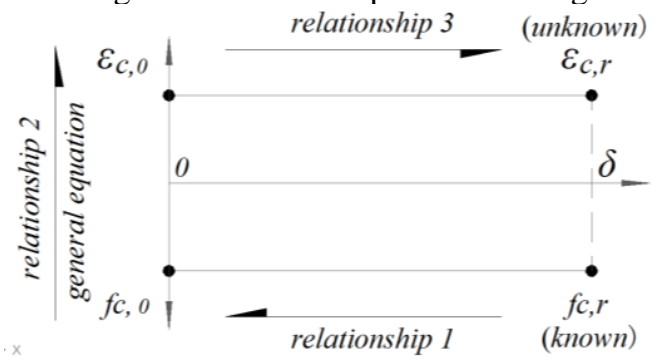

Figure 4. Method for establishing the calculation equation of RAC peak

\section{B. Derivation of Calculation Equation}

Because of the recycled aggregate and natural aggregate selected by each scholar in their specimens is different, so in order to eliminate the error caused by the raw materials of specimens, this paper assumes that the sample with the replacement rate of 0 in each scholar's specimens is completely satisfied with the code of NAC. Based on this assumption, we can find the ratio relations between RAC and NAC. The prism compressive strength ratio relations of experimental data in each group plotted in Fig. 5, the straight lines in figure indicate change trend of test data in each group.

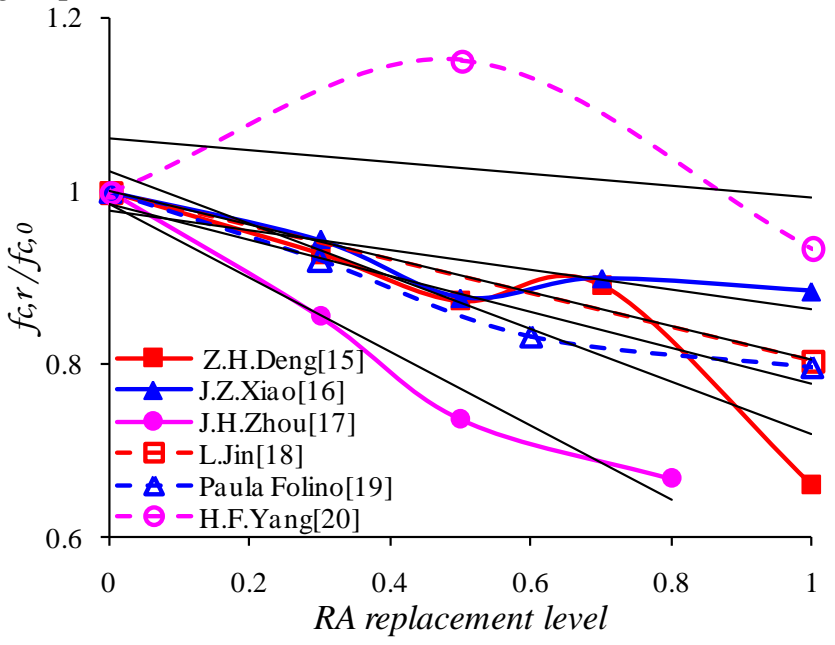

Figure 5. Prism compressive strength ratios vary with RA replacement level

Use $\mathrm{K}_{1}$ to indicate the slopes of straight lines in Figure 5, $K_{1}$ is given in Table II where 6 values can be seen for all groups of test data.

Similarly to prism compressive strength ratios, the peak strain ratios are shown in Fig. 6. The slopes of straight lines in Fig. 6 are indicated by $K_{2}$ which is also given in Table II .

TABLE II. VALUES OF K1 AND K2

\begin{tabular}{c|rrrr}
\hline \multirow{2}{*}{$\mathrm{K}_{1}$} & $-0.304 ;$ & $-0.114 ;$ & $-0.426 ;$ & $-0.195 ;$ \\
\hline \multirow{2}{*}{$\mathrm{K}_{2}$} & $0.386 ;$ & $0.189 ;$ & -0.068 & \\
\hline
\end{tabular}

Using Grubbs method to determine the dispersion of $\mathrm{K}_{\mathrm{i}}$ value, the dispersion can be expressed by the following formula:

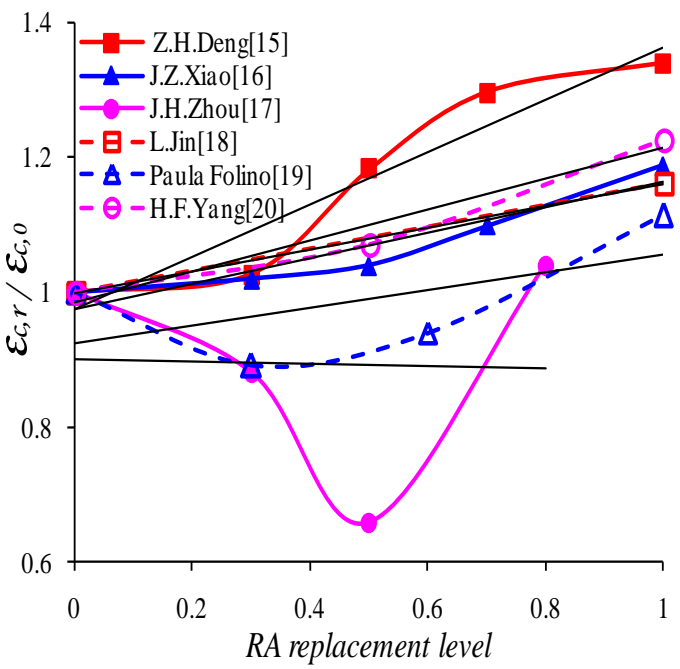

Figure 6. Peak strain ratios vary with RA replacement level 


$$
g_{\text {in }}=\left|K_{\text {in }}-\overline{K_{i}}\right| / S
$$

Where $g_{\text {in }}$ is the dispersion of $K_{i n}, \overline{K_{i}}$ is the average value of $K_{i}, S$ is the standard deviation of $K_{i}$. The multiplicative inverse of $g_{\text {in }}$ can be regard as the weight value of $K_{\text {in }}$, labeled as $\xi_{\text {in }}$, the expression is:

$$
\xi_{\text {in }}=1 / g_{\text {in }}
$$

The weighted average value of $\mathrm{K}_{\mathrm{i}}$ can be calculated by the following equation:

$$
\tilde{K}_{i}=\frac{\sum_{n=1}^{n} K_{i n} \times \xi_{i n}}{\sum_{n=1}^{n} \xi_{i n}}
$$

Importing the $\mathrm{K}_{\mathrm{i}}$ values of Table II into equation (5), we can get the weighted average value of $\tilde{K}_{i} \cdot \tilde{K}_{1}=-0.20 ; \tilde{K}_{2}=0.18$

According to the research method that shown in Figure 4, establishing the following relationships:

$$
\begin{aligned}
& f_{c, r}=\left(1+\tilde{K}_{1} \delta\right) f_{c, 0} \\
& \varepsilon_{c, r}=\left(1+\tilde{K}_{2} \delta\right) \varepsilon_{c, 0}
\end{aligned}
$$

Where $f_{c, r}$ is the prism compressive strength of RAC, $f_{c, 0}$ is the prism compressive strength of NAC, $\varepsilon_{c, r}$ is the peak strain of RAC, $\varepsilon_{c, 0}$ is the peak strain of NAC, $\delta$ is the RA replacement rate.

The literature [21] and Chinese code [22] proposes the following expression for peak strain of NAC.

$$
\varepsilon_{c, 0}=\left(700+172 \sqrt{f_{c, 0}}\right) \times 10^{-6}
$$

Equation (6), (7) and (8) may therefore be used for the peak strain calculation equation of RAC, the expression is as follows:

$$
\varepsilon_{c, r}=\left(1+\tilde{K}_{2} \delta\right)\left[700+172 \sqrt{\frac{f_{c, r}}{\left(1+\tilde{K}_{1} \delta\right)}}\right] \times 10^{-6}
$$

Taking $\tilde{K}_{i}$ values into the equation (9), the final calculation equation of RAC peak strain is:

$$
\varepsilon_{c, r}=(1+0.18 \delta)\left[700+172 \sqrt{\frac{f_{c, r}}{(1-0.20 \delta)}}\right] \times 10^{-6}
$$

\section{CALCULATION RESUlt ANALYSIS}

\begin{tabular}{|c|c|c|c|}
\hline $\begin{array}{c}\text { Prism } \\
\text { compressive } \\
\text { strength } \\
\text { (MPa) }\end{array}$ & $\begin{array}{c}\text { Chinese } \\
\text { code [22] } \\
\left(\mathbf{x 1 0 ^ { - 3 } )}\right. \\
\end{array}$ & $\begin{array}{c}\mathrm{Eq}(\mathbf{1 0}) \\
\text { calculation result } \\
\left(\times \mathbf{x 1 0}^{-3}\right)\end{array}$ & $\begin{array}{c}\text { Eq (1) } \\
\text { calculation } \\
\text { result }\left(\mathbf{x 1 0}^{-3}\right)\end{array}$ \\
\hline 25 & 1.560 & $1.560(0 \%)$ & $1.824 \quad(17 \%)$ \\
\hline 30 & 1.640 & $1.642(0.1 \%)$ & $1.962(20 \%)$ \\
\hline 35 & 1.720 & $1.718(-0.1 \%)$ & $2.086(21 \%)$ \\
\hline 40 & 1.790 & $1.788 \quad(-0.1 \%)$ & $2.199(23 \%)$ \\
\hline 45 & 1.850 & $1.854(0.2 \%)$ & $2.304(25 \%)$ \\
\hline 50 & 1.920 & $1.916(-0.2 \%)$ & $2.402(25 \%)$ \\
\hline $\begin{array}{c}\text { Prism } \\
\text { compressive } \\
\text { strength } \\
(\mathrm{MPa}) \\
\end{array}$ & $\begin{array}{c}\text { EC2 [23] } \\
\left(\times 10^{-3}\right)\end{array}$ & $\begin{array}{c}\mathbf{E q}(\mathbf{1 0}) \\
\text { calculation result } \\
\left(\mathbf{x 1 0}^{-3}\right)\end{array}$ & $\begin{array}{c}\text { Eq }(1) \\
\text { calculation } \\
\text { result }\left(\mathbf{x 1 0}^{-3}\right)\end{array}$ \\
\hline 25 & 1.743 & $1.560(-10 \%)$ & $1.824(5 \%)$ \\
\hline 30 & 1.845 & $1.642(-11 \%)$ & $1.962(6 \%)$ \\
\hline 35 & 1.935 & $1.718(-11 \%)$ & $2.086 \quad(8 \%)$ \\
\hline 40 & 2.017 & $1.788(-11 \%)$ & $2.199(9 \%)$ \\
\hline 45 & 2.092 & $1.854(-11 \%)$ & $2.304(10 \%)$ \\
\hline 50 & 2.162 & $1.916(-11 \%)$ & $2.402(11 \%)$ \\
\hline
\end{tabular}

Eq (1) and Eq (10) incorporated the parameter of RA replacement rate, when this parameter is 0 ; the calculation value of equations is the peak strain of NAC. Table III listed out the peak strain that calculated by Eq (1), Eq (10) and the value cited from codes.

TABLE III. CALCULATION RESUlts OF EQ (1) AND EQ (10) COMPARED WITH CODE'S VALUES

Table III shows the deviation of NAC peak strain calculation value where it can be seen that the maximum deviation value of Eq (1) and Eq (10) is $25 \%$ and $0.2 \%$ by compared with Chinese code. Compared with EC2, the calculation errors of Eq (1) and Eq (10) are similar. It shows that the Eq (10) can well predict the peak strain of NAC.

For RAC with prism compressive strength of $30 \mathrm{MPa}$, $40 \mathrm{MPa}, 50 \mathrm{MPa}$, using the Eq (1) and Eq (10) to calculate the peak strain under different RA replacement level, the results shown in Fig. 7.

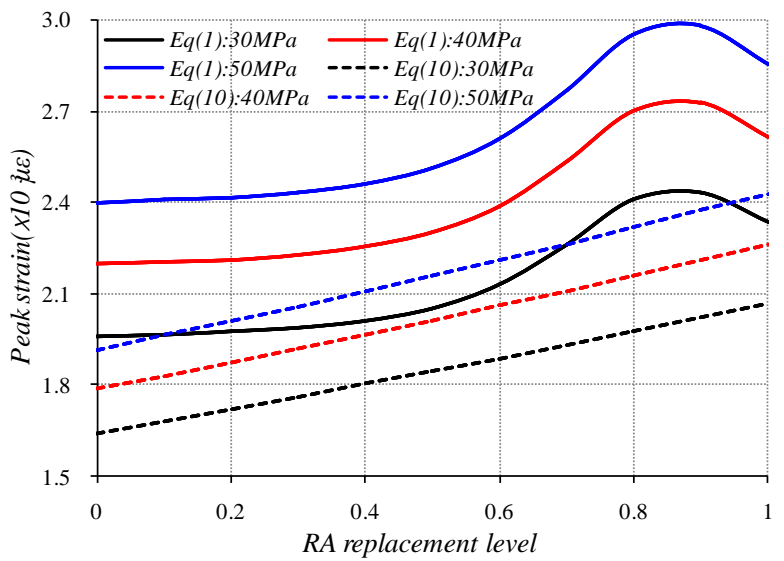

Figure 7. Comparison between Eq (1) and Eq (10) 
It shows that when RA replacement rate is among 0.8 to 0.9 , there is a bulge on the calculation curve of Eq (1), this phenomenon cannot be explained by the previous experimental data. The calculation values of $\mathrm{Eq}$ (10) are generally less than that of Eq (1), the gap is most pronounced in low and high RA replacement level. Furthermore, the difference of calculation results of $\mathrm{Eq}$ (1) and $\mathrm{Eq}$ (10) is more significant with the increase of prism compressive strength; this is consistent with the comparison results in Table III.

Values of Table IV were obtained by collecting the test data of previous studies which are used for verification of equation, the RAC prism compressive strength in table 4 is based on experimental specimen of $150 \mathrm{mmx} 150 \mathrm{~mm} \times 300 \mathrm{~mm}$, some strength values has been converted according to the requirement of calculation. Compared the calculation results of equations with 42 collected test data, Fig. 8 presents the calculation errors.

TABLE IV. DATABASE FOR VERIFICATION OF EQUATION

\begin{tabular}{|c|c|c|c|}
\hline Literature & $\begin{array}{c}\mathrm{RA} \\
\text { replacement } \\
\text { rate } \\
\end{array}$ & $\begin{array}{c}\text { Prism } \\
\text { compressive } \\
\text { strength(MPa) }\end{array}$ & $\begin{array}{c}\text { Peak strain } \\
\left(\mathrm{x} 10^{-3}\right)\end{array}$ \\
\hline \multirow{8}{*}{$\begin{array}{c}\text { G-F.Belén } \\
{[14]}\end{array}$} & 0 & 44.80 & 1.900 \\
\hline & 0.2 & 43.70 & 1.890 \\
\hline & 0.5 & 37.50 & 1.900 \\
\hline & 1 & 40.50 & 2.190 \\
\hline & 0 & 31.90 & 1.740 \\
\hline & 0.2 & 31.70 & 1.990 \\
\hline & 0.5 & 32.40 & 1.950 \\
\hline & 1 & 30.10 & 2.160 \\
\hline \multirow{3}{*}{ M-L.Isabel [5] } & 0 & 30.50 & 2.100 \\
\hline & 0.5 & 26.80 & 2.300 \\
\hline & 1 & 20.40 & 2.500 \\
\hline \multirow{4}{*}{ T.Du[6] } & 1 & 30.52 & 2.559 \\
\hline & 1 & 35.57 & 2.690 \\
\hline & 1 & 39.02 & 2.787 \\
\hline & 1 & 40.63 & 2.983 \\
\hline \multirow{17}{*}{ J.T.Du[24] } & 1 & 24.31 & 1.800 \\
\hline & 1 & 25.12 & 1.800 \\
\hline & 1 & 23.34 & 2.200 \\
\hline & 1 & 23.47 & 1.200 \\
\hline & 1 & 24.47 & 1.600 \\
\hline & 1 & 24.88 & 1.200 \\
\hline & 1 & 19.69 & 1.600 \\
\hline & 1 & 19.64 & 2.100 \\
\hline & 1 & 17.26 & 1.300 \\
\hline & 1 & 17.15 & 1.300 \\
\hline & 1 & 17.71 & 1.500 \\
\hline & 1 & 17.16 & 1.400 \\
\hline & 1 & 18.91 & 1.400 \\
\hline & 1 & 16.89 & 1.400 \\
\hline & 1 & 16.90 & 1.200 \\
\hline & 1 & 16.08 & 1.600 \\
\hline & 1 & 19.79 & 1.600 \\
\hline \multirow{3}{*}{$\begin{array}{c}\text { Marco } \\
\text { Breccolotti } \\
{[25]} \\
\end{array}$} & 0 & 49.95 & 2.769 \\
\hline & 0.5 & 43.50 & 2.845 \\
\hline & 1 & 29.81 & 2.592 \\
\hline \multirow{4}{*}{ W.L.Cao[26] } & 0 & 68.56 & 2.080 \\
\hline & 0.33 & 60.94 & 2.116 \\
\hline & 0.66 & 60.34 & 2.186 \\
\hline & 1 & 57.36 & 2.187 \\
\hline \multirow{3}{*}{ Y.L.Hou[27] } & 0 & 26.90 & 1.758 \\
\hline & 0.4 & 26.90 & 1.841 \\
\hline & 1 & 26.50 & 2.056 \\
\hline
\end{tabular}

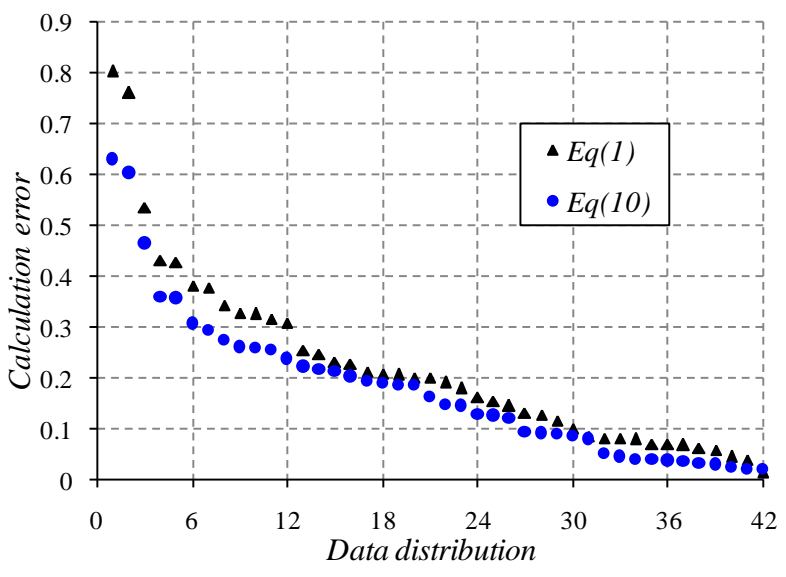

Figure 8. Calculation errors between equations and test data

From Fig. 8, it can be seen that the calculation error of the Eq (10) is less than that of Eq (1), the average prediction error of Eq (1) and Eq (10) is $22.5 \%$ and $18.1 \%$. So it is clear that for the same test data, the proposed expression given by $\mathrm{Eq}(10)$ is more suitable for the prediction of RAC peak stain.

\section{CONCLUSIONS}

In this paper, a statistical analysis of peak strain test data was carried by new method. Based on the results of analysis, a new calculation equation was deduced for predicting the peak strain of RAC. The results of this study can provide reference for engineers and designers. The main conclusions of this paper are as follows:

1. The peak strain between RAC and NAC has a greater difference. For RAC, the RA replacement rate has a great influence on the peak strain.

2. The deduced equation of peak strain can achieve the seamless connection with the Chinese code which is suitable for both NAC and RAC.

3. Compared with the existing equations, the proposed equation in this paper can predict the RAC peak strain preferably.

\section{ACKNOWLEDGMENT}

The presented research is conducted under the financial support of the Natural Science Foundation of China (No: 51468003), the Specialized Research Fund for the Doctoral Program of Higher Education (No: 20134501110001) and Guangxi Science Research and Technology Development Project (No: GKZ14124005-1-2).

\section{REFERENCES}

[1] P.J. Nixon, "Recycled concrete as an aggregate for concrete-a review," Materials and Structures, vol. 65, Sep. 1978, pp. 371-378, doi:10.1007/BF02473878.

[2] T.C. Hansen, "Recycled aggregates and recycled aggregate concrete second state-of-the-art report developments 1945-1985," Materials and Structures, vol. 19, 1986, pp. 201-246, doi:10.1007/BF02472036.

[3] G-F.Belén, M-A.Fernando, E-L.Javier, S-P.Sindy, "Effect of recycled coarse aggregate on damage of recycled concrete," Materials and Structures, vol. 44, 2011, pp. 1759-1771, doi:10.1617/s11527-011-9736-7. 
[4] W. George, G. Elhem, G. Hector, "Mix design and properties of recycled aggregate concretes: applicability of Eurocode 2," International Journal of Concrete Structures and Materials, vol. 9, 2015, pp. 1-20, doi:10.1007/s40069-014-0087-y.

[5] M-L.Isabel, M-A.Fernando, V-H.Cristina, P-O.Juan Luis, "Properties of plain concrete made with mixed recycled coarse aggregate," Construction and Building Materials, Non Destructive Techniques for Assessment of Concrete, vol. 37, 2012, pp. 171-176, doi:10.1016/j.conbuildmat.2012.07.045.

[6] T.Du, W.H.Wang, Z.X.Liu, et al, "The complete stress-strain curve of recycled aggregate concrete under uniaxial compression loading," Journal of Wuhan University of Technology-Mater. Sci. Ed, vol. 25, 2010, pp. 862-865, doi:10.1007/s11595-010-0109-9.

[7] J.S.Ryu, "An experimental study on the effect of recycled aggregate concrete properties," Magazine of Concrete Research, vol. 54, 2002, pp. 7-12, doi: 10.1680/macr.2002.54.1.7.

[8] I.B.Topcu, N.F.Guncan, "Using waste concrete as aggregate," Cement and Concrete Research, vol. 25, 1995, pp. 1385-1390, doi: 10.1016/0008-8846(95)00131-U.

[9] N.K.Bairagi, R.Kishore, "Behavior of concrete with differe-nt proportions of natural and recycled aggregate resource ,"Conservation and Recycling, vol. 9, 1993, pp. 109-126, doi:10.1016/0921-3449(93)90036-F.

[10] J.Z.Xiao, J.B.Li, "Mechanical properties of recycled aggregate concrete under uniaxial loading," Cement and Concrete Research, vol. 35, 2005, pp. 1187-1194, doi:10.1016/j. cemconres.2004.09.020.

[11] T.Du, H.Q.Li, X.G.Wu, Y.W.Qin, "The compression-deformation behavior of concrete with various modified recycled aggregates," Journal of Wuhan University of Technology-Mater. Sci. Ed, vol. 20, 2005, pp. 127-129, doi:10.1007/BF02838509.

[12] M. Chakradhara Rao, S.K. Bhattacharyya, S.V. Barai, "Influence of field recycled coarse aggregate on properties of concrete," Materials and Structures, vol. 44, 2011, pp. 205-220, doi:10.1617/s11527-0109620-x.

[13] Sohaib Ahmad, Kypros Pilakoutas, Qaiser uz ZamanKhan, Kyriacos Neocleous, "Stress-strain model for low-strength concrete in uniaxial compression,” Arab J Sci Eng, vol. 40, 2015, pp. 313-328, doi:10.1007/s13369-014-1411-1.

[14] G-F.Belén, M-A.Fernando, C-L. Diego, S-P.Sindy, "Stress-strain relationship in axial compression for concrete using recycled saturated coarse aggregate," Construction and Building Materials, vol. 25, 2011, pp. 2335-2342, doi:10.1016/j.conbuildmat.2010.11.031.
[15] Z.H.Deng, H.F.Yang, J.Lin, S.H.Wen, "Experimental study on the stress-strain curve of recycled concrete," Concrete, vol. 11, 2008, pp. 22-24. (in Chinese)

[16] J.Z.Xiao, "Experimental investigation on complete stress-strain curve of recycled concrete under uniaxial loading," Journal of TongJi University (Natural Science), vol. 35, 2007, pp. 1445-1449. (in Chinese)

[17] J.H.Zhou, H.J.He, X.H.Meng, Y.Z.Yang, "Basic mechanical properties of recycled concrete experimental study," Journal of Shenyang Jianzhu University (Natural Science), vol. 26, 2010, pp. 464-468. (in Chinese)

[18] L.Jin, "Experimental study on mechanical properties of recycled concrete," New Building Materials, vol. 7, 2006, pp. 11-13. (in Chinese)

[19] Paula Folino,Hernán Xargay, "Recycled aggregate concretemechanical behavior under uniaxial and triaxial compression," Construction and Building Materials, vol. 56, 2014, pp. 21-31, doi: 10.1016/j.conbuildmat.2014.01.073

[20] H.F.Yang, "Research on compression constitutive relationship and bondslip properties of recycled concrete," Guangxi University, 2012. (in Chinese)

[21] Z.H.Guo, "Strength and deformation of concrete - the test foundation and constitutive relation," Beijing:Tsinghua University Press, 1997. (in Chinese)

[22] GB50010-2010. "Code for design of concrete structures," Beijing: China Architecture \& Building Press, 2010. (in Chinese)

[23] EC2. "Design of concrete structures-Part 1 General rules and rules for buildings," BS EN-1992-1-1:200, 2004

[24] J.T.Du, "An experimental and numerical study on stress-strain relationship of recycled concrete under uniaxial loading," Shanghai:Tongji University,2008. (in Chinese)

[25] Marco Breccolotti, Antonella D’Alessandro, Francesca Roscini, et al, "Investigation of stress - strain behaviour of recycled aggregate concrete under cyclic loads," Environmental Engineering and Management Journal, vol. 14, 2015, pp. 1543-1552.

[26] W.L.Cao, K.R.Zhu, W.Jiang, et al, "Experimental study on stressstrain constitutive relationship of high strength recycled concrete," Journal of Natural Disasters, vol. 25, 2016, pp. 167-172.(in Chinese)

[27] Y.L.Hou, X.Y.Lv, G.Zheng, et al, "Stress-strain relationship of recycled aggregate concrete under uniaxial compression," Bulletin of the Chinese Ceramic Society, vol. 34, 2015, pp. 3102-3105. (in Chinese) 